\title{
EXTRA-GENITAL MULLERIAN ADENOSSARCOMA WITH SARCOMATOUS OVERGROWTH: CASE REPORT OF A RARE NEOPLASIA
}

Paulo Laginha(1); Fabio Laginha(2); Cid Gusmao(3); Evandro Pinheiro(4); Marcelo Simonsen(5)

\section{OBJECTIVE}

Demonstrate recurrence and the histological progression of a rare extra-genital Mullerian Adenosarcoma in a High Grade Carcinossarcoma.

\section{BACKGROUND}

Mullerian Adenosarcomas (MAS) are rare mixed tumors (glandular epithelium associated with sarcoma) that occur mainly in the uterus and rarely in extrauterine locations. Generally, MAS presents clinically indolent behaviour, whereas MAS with sarcomatous overgrowth, which is defined by the presence of a highgrade sarcomatous component in at least $25 \%$ of the tumour, is extremely aggressive and is characterized by recurrence and metastasis at an early stage.

\section{CASE REPORT}

D.C.46 years' complaint of abdominal pain and feces on tape. Physical examination showed a large fixed mass filling the pelvic cavity. Magnetic Resonance showed a lobulated, retrouterine mass up to $14 \times 11 \mathrm{~cm}$, heterogeneous with blood component, without definite capsule, peritoneal thickening, moderate ascites and CA125: 400UI dosage. The patient underwent complete staging surgery in 2010. The pathological anatomical results were Low-Grade Mullerian Adenossarcoma with sarcomatous overgrowth of Retroperitoneum.
The patient has been alive in follow-up since then. Submitted to 6 surgeries (second surgery with HIPEC) for recurrences and clinically treated with 7 differents quimioterapics. The hystological results have changed over the years and the last one was High-Grade Carcinossarcoma.

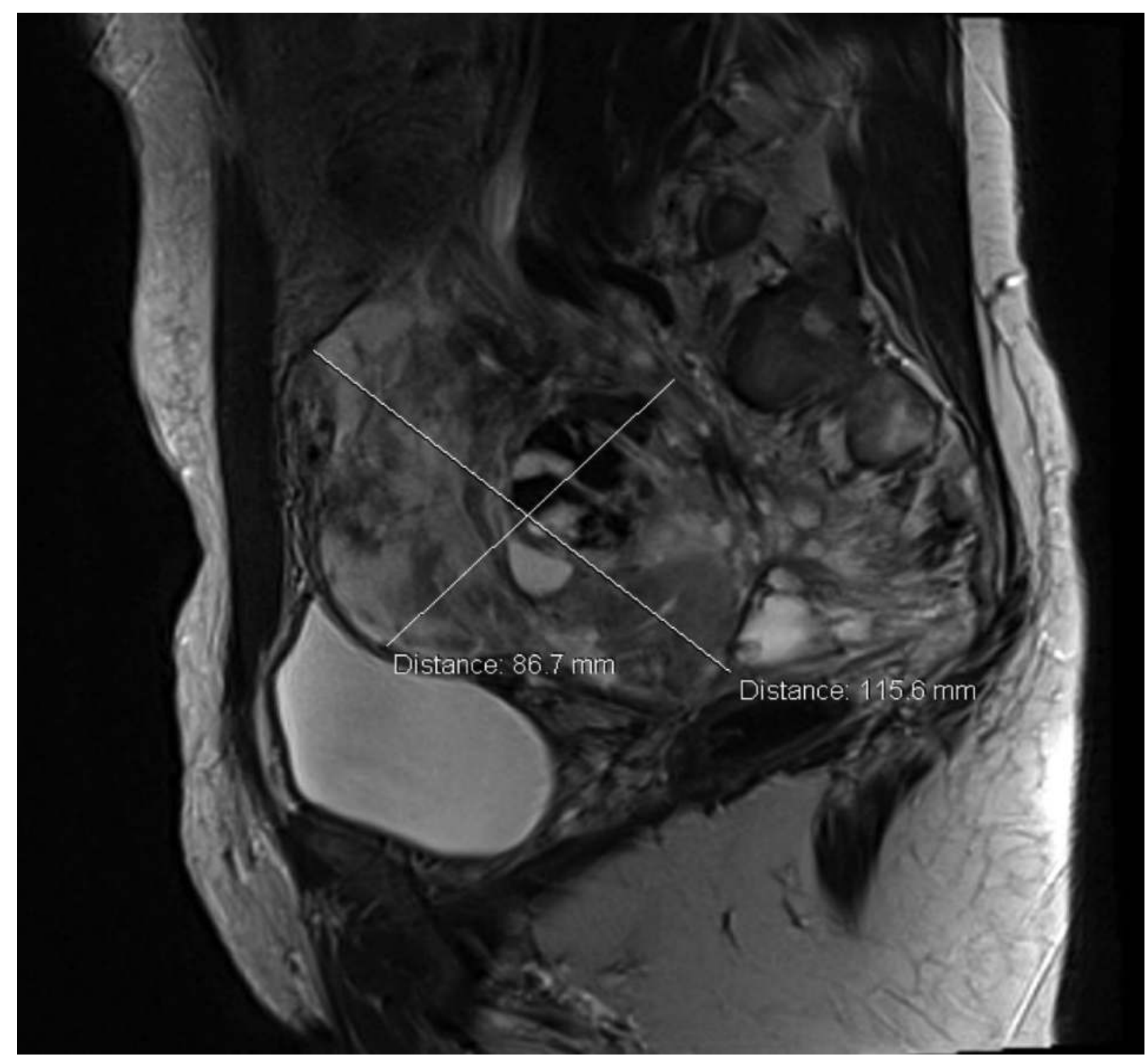

\section{LITERATURE REVIEW AND CONCLUSION}

From 1974 to 2016, shows a total of 41 cases of extra-genital MAS, 2/41 of retroperitoneum. No consistent data for extragenital MAS are available because these are extremely rare and the standardization of treatment is difficult because of the limited experience. This is one of the longest overall survivals recorded case of extra-genital MAS of retroperitoneum. 